\title{
THE RELATION BETWEEN IN VITRO CONTRACTIONS OF THE RAT SEMINIFEROUS TUBULES AND THE CYCLIC STAGE OF THE SEMINIFEROUS EPITHELIUM
}

\author{
O. SUVANTO AND M. KORMANO \\ Department of Anatomy, University of Helsinki, \\ Helsinki 17, Finland
}

(Received 20th December 1968)

\begin{abstract}
Summary. Pieces of rat seminiferous tubules were studied in KrebsRinger-glucose solution at $35^{\circ} \mathrm{C}$ in a microscope stage chamber, with special reference to the frequency, depth and length of their contractions. Contractile and non-contractile pieces were dissected and the stage of the cycle was determined histologically.

The mean depth of the contractions was $12 \mu$ and their mean frequency was five/min. The mean length of the indentation caused by a single contraction was $67 \mu$. There was an average of one contractile area for each $240 \mu$ length of tubule. Spontaneous contractions were seen to occur at any stage of the cycle. Non-contractile pieces of the tubule were also found independent of the stage of the cycle. The observations are compatible with the view that the contractions promote the transport of spermatozoa and tubular fluid to the rete testis.
\end{abstract}

\section{INTRODUCTION}

Spontaneous contractions of the rat seminiferous tubules were first observed by Roosen-Runge (1951). He suggested that the Sertoli cells are responsible for the movements. Later, Clermont (1958) demonstrated that, between the two layers of the tubular basement membrane, there are smooth muscle-like cells. Cells similar to those seen in the rat testis were eventually demonstrated in the basement membrane of the seminiferous tubule in several other species, such as mice (Baillie, 1962; Ross, 1968) and man (Lacy, 1962; Ross \& Long, 1966). These cells contain intra-cytoplasmic filaments (Glermont, 1958; Lacy \& Rotblat, 1960; Ross, 1968), but their general arrangement is not typical of smooth muscle or of the contractile myo-epithelial cells of glands. They also acquire their ultrastructural maturity (Leeson \& Leeson, 1963; Ross, 1968) very late, just before the onset of puberty.

Clermont (1958) was the first to attribute the contractile activity of seminiferous tubules to the smooth muscle-like cells. Later, both spontaneous and oxytocin-induced contractions of the tubules were shown to begin in the rat at that age when intra-cytoplasmic filaments first appear in these cells (Leeson \& Leeson, 1963; Niemi \& Kormano, 1965; Kormano \& Kokko, unpublished observations). 
The structures responsible for the tubular contractions are thus well documented but their functional significance still remains to be elucidated. Both Roosen-Runge (1951) and Niemi \& Kormano (1965) observed that all segments of the tubules do not contract equally; the vigour of the contractions varies greatly in different tubules and there are some lengths of tubule which do not contract at all. Consequently, it was suggested that the inequality of the contractions may be related to the stage of the cycle of the seminiferous epithelium. There is, however, no direct evidence of this kind of relationship. In the present study, the spontaneous contractions of the rat seminiferous tubule in vitro have been carefully characterized and compared with the cyclic stage of the seminiferous epithelium.

\section{MATERIAL AND METHODS}

Adult, male, Sprague-Dawley rats were anaesthetized by intraperitoneal injection of $50 \mathrm{mg} / \mathrm{kg}$ pentobarbitone sodium (Nembutal, Abbot). Seminiferous tubules were dissected from these rats after bloodless incision of the tunica. Pieces of seminiferous tubule, 2 to $3 \mathrm{~cm}$ in length, were suspended in a few drops of Krebs-Ringer-glucose solution on cover-slips in a microscope stage chamber kept at $35^{\circ} \mathrm{C}$. They were examined in transmitted light at a magnification of $\times 250$. Contractile and non-contractile pieces were then dissected from these tubules. Longitudinally cut, $5 \mu$, serial paraffin sections from the tubules were stained by the PAS-haematoxylin-eosin method (Leblond \& Clermont, 1952). The stage of the cycle of the spermatogenic epithelium in these specimens was determined according to Leblond \& Glermont (1952). The ratio of contractile to non-contractile pieces was also studied at each stage of the cycle.

\section{RESULTS}

\section{Characterization of the contractions}

The outer diameter of the seminiferous tubules of the adult rat testis was $300 \pm 6 \mu$ by vital microscopy. The diameter of the tubular lumen varied to some extent at different stages of the spermatogenic cycle, the average being $128 \pm 15$ $\mu$. The terminology used to describe the contractions is presented graphically in Text-fig. 1. The depth of the indentations in the basement membrane caused by a single contraction varied from 5 to $25 \mu$, the mean depth being $12 \mu$.

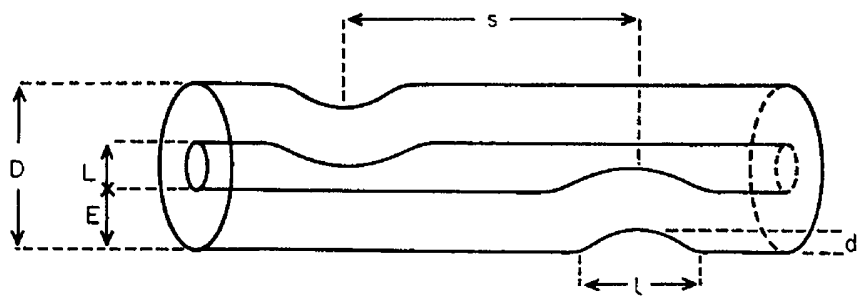

TEXT-FIG. 1. Diagrammatic description of the terminology used to describe the contractions of the seminiferous tubules. Abbreviations: $\mathrm{D}=$ outer diameter of the tubule; $\mathbf{E}=$ thickness of the seminiferous epithelium; $\mathrm{L}=$ diameter of the tubular lumen; $d=$ depth of the contraction; $1=$ length of the contraction; $s=$ distance between two simultaneous contractions. 
Contractions of the boundary tissue also caused a corresponding narrowing of the lumen of the tubule and visible movement of spermatozoa and tubular fluid, although the change in tubular diameter caused by the contraction was only 2 to $8 \%$. The frequency of the contractions at each contractile site was five/min on average. No correlation was found between the frequency and depth of the contractions at each site (Text-fig. 2). The average length of the indentation induced by a single contraction was $67 \mu$. The contractions were local and not circular like peristaltic contractions in general (Text-fig. 1).

Generally, one contraction was usually visible for each $480-\mu$ length of tubule. However, since only about half of the surface of a tubule was visible by vital microscopy, the real distance between two simultaneously contracting areas was, therefore, approximately half the observed distance, namely $240 \mu$.

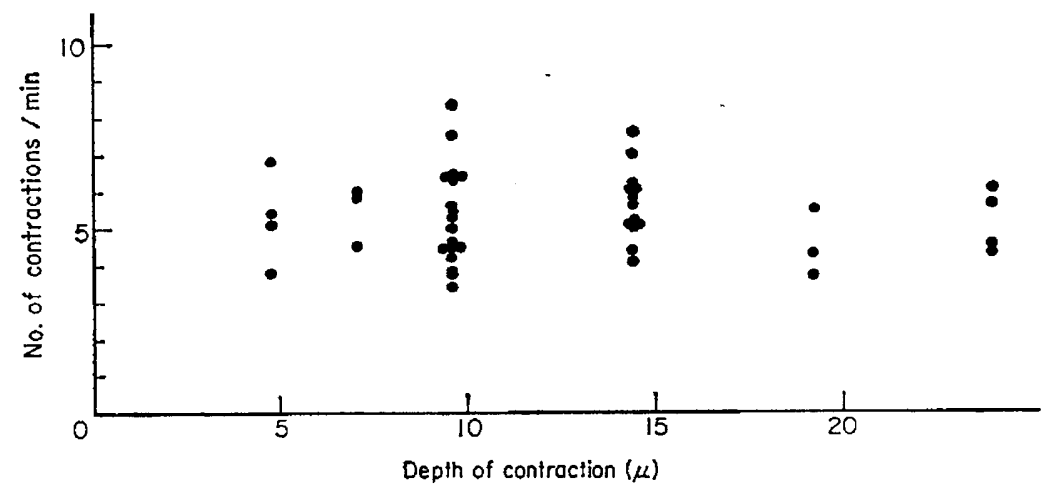

TEXT-FTG. 2. Relationship between depth and frequency of contractions of the rat seminiferous tubules.

The relationship of the contractions to the stage of the spermatogenic epithelium

Altogether 128 contractile and ninety non-contractile segments were assessed for this part of the study. Most tubules were contractile along their whole length and only short non-contractile parts were seen in the middle of actively contracting lengths of tubule. No attempt was made to classify the degree of contractile activity in this part of the study, the pieces selected being either clearly contractile or totally devoid of visible spontaneous contractile activity.

Mechanical stimulation, such as stretching, seemed to increase the frequency and depth of the contractions (and even to induce contractions in non-motile pieces of tubule). The dissected pieces were, therefore, handled very carefully.

The number of contractile and non-contractile tubules at each stage of the cycle is presented in Table 1. This shows that, in general, spontaneous contractions were seen in the tubules at any stage of the cycle of the seminiferous epithelium. Similarly, non-contractile pieces of tubule could also be identified at any stage of the cycle.

There are no striking differences in the ratio of the number of contractile to non-contractile segments of tubule at each stage (Table 1). However, they show certain general trends, which may reflect the influence of the stage of the cycle on the contractility of the tubule wall. In the stages which are characterized by the presence of young spermatids in the Golgi phase (Stages I to III), 


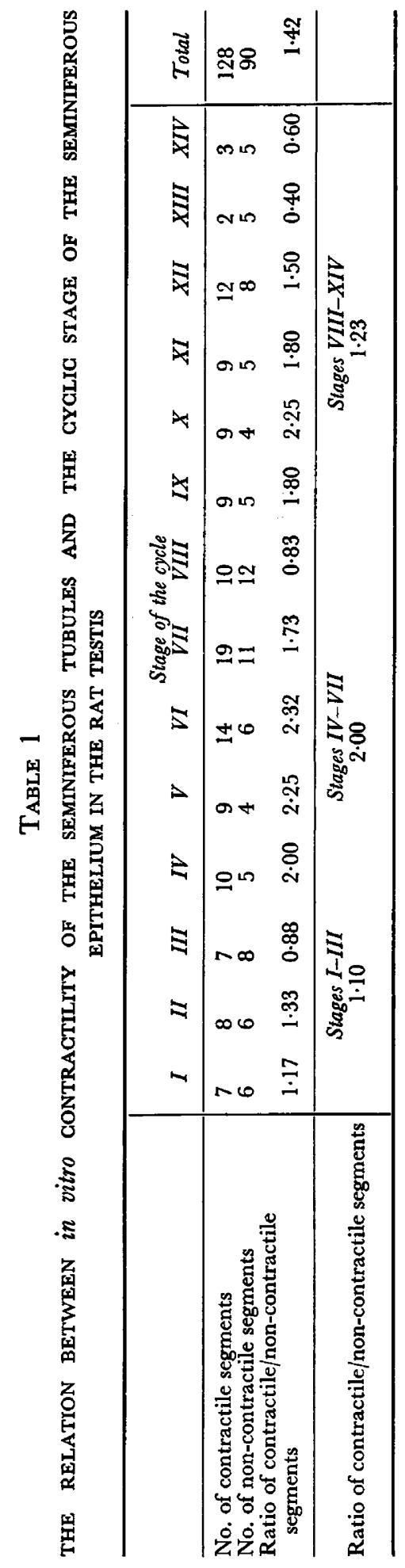


the ratio of contractile to non-contractile tubules is slightly lower than the mean ratio of the whole material, 22:20 and 128:90, respectively. On the other hand, in the stages during which the young spermatids are in the cap phase (Stages IV to VII) and in which maturing spermatids begin to move towards the lumen before their final detachment, non-contractile tubules were relatively rare (contractile/non-contractile ratio 52:26). Stages XIII and XIV, on the other hand, usually appeared more often in the non-contractile group than the segments. All these differences were statistically insignificant.

\section{DISCUSSION}

The present study shows that contractile movements in the seminiferous tubules are rather localized and cause relatively little volume change in the tubule. Also, the depth of the contractions, as seen by vital microscopy, is independent of their frequency. The question of the regulation of these contractile movements is still not clear. Baumgarten \& Holstein (1967) have demonstrated adrenergic nerve fibres in the human testis but, in a more recent study, these authors concluded that the sympathetic-adrenergic innervation is of little importance for the functional integrity of the human testis (Baumgarten, Falck, Holstein, Owman \& Owman, 1968). No innervation has ever been documented in the contractile cells of the rat seminiferous tubule. Thus, Norberg, Risley \& Ungerstedt (1967) concluded that contractility in the seminiferous tubules of the rat is myogenic and spontaneous. However, as the present study shows, variations exist in the contractility of seminiferous tubules and, therefore, some kind of regulatory mechanism, such as internal pressure caused by tubular fluid secretion (Setchell, 1967b), hormonal influences (Risley, 1959; Voglmayr, Waites \& Setchell, 1966) or even the significant quantities of glutamic acid and other amino-acids which are synthesized within the tubules (Setchell, personal communication) should be considered in this connection.

Using a very ingenious method of collecting the testicular fluid of the ram, Setchell and his collaborators (Setchell, 1967a, b; Voglmayr et al., 1966) have been able to obtain evidence that, in the seminiferous tubule, elaboration of spermatozoa and secretion of fluid are, to a great extent, independent functions. It has now to be determined to what degree the contractile movements in the tubules represent another independent function and to what degree these movements influence (1) the release of spermatozoa from the seminiferous epithelium and (2) the transport of fluid and spermatozoa along the tubules towards the rete testis.

Correlation of the contractions of the seminiferous tubules with phases of the spermatogenic cycle would be consistent with the hypothesis that such contractions are significant in the mechanisms of sperm release. Independence of the degree of contractility from the cyclical status within the tubule would suggest the second possibility, i.e. a pure pumping activity to promote fluid movement along the tubule. In contrast to earlier suggestions (Roosen-Runge, 1951; Niemi \& Kormano, 1965), the present results show that, in vitro, the contractile activity of the smooth muscle-like cells within the tubular basement membrane is not correlated with the cycle of the epithelium. This is in agreement with the 
speculations of Ross (1968), who also suggested that the contractions promote fluid transport rather than sperm release from the epithelium. However, the slight differences between the ratios of contractile to non-contractile segments at each stage of the cycle suggest that some kind of relationship between the contractions and the release of spermatozoa cannot be completely excluded.

\section{REFERENCES}

BAILLIE, A. H. (1962) Histochemical differentiation of the basement membrane of the mouse seminiferous tubule. Q. Fl microsc. Sci. 103, 385.

Baumgarten, H. G., Falck, B., Holstein, A.-F., Owman, Gh. \& Owman, T. (1968) Adrenergic innervation of the human testis, epididymis, ductus deferens and prostate: A fluorescence microscopic and fluorimetric study. Z. Zellforsch. mikrosk. Anat. 90, 81.

Baumgarten, H. G. \& Holstein, A.-F. (1967) Catecholamin-inhaltige Nervenfasern im Hoden des Menschen. Z. Zellforsch. 79, 389.

Clermont, Y. (1958) Contractile elements in the limiting membrane of the seminiferous tubules of the rat. Expl Cell Res. 15, 438.

LACY, D. (1962) Certain aspects of testis structure and function. Br. med. Bull. 18, 205.

LACY, D. \& Rotblat, J. (1960) Study of normal and irradiated boundary tissue of the seminiferous tubules of the rat. Expl Cell Res. $21,49$.

Leblond, C. P. \& Clemmont, Y. (1952) Definition of the stages of the cycle of the seminiferous epithelium in the rat. Ann. N.Y. Acad. Sci. 55, 548.

Lezson, G. R. \& Leeson, T. S. (1963) The postnatal development and differentiation of the boundary tissue of the seminiferous tubule of the rat. Anat. Rec. 147, 243.

Nizmi, M. \& Kormano, M. (1965) Contractility of the seminiferous tubule of the postnatal rat testis and its response to oxytocin. Annls Med. exp. Biol. Fenn. 43, 40.

Norberg, K.-A., RusLey, P. L. \& Ungerstedt, U. (1967) Adrenergic innervation of the male reproductive ducts in some mammals. I. The distribution of adrenergic nerves. Z. Zellforsch. mikrosk. Anat. 76, 278.

RusLex, P. L. (1959) Hormone effects on the in vivo contractile behaviour of the ductus epididymis of the rat. Anat. Rec. 133, 329.

Roosen-Runge, E. C. (1951) Motions of the seminiferous tubules of rat and dog. Anat. Rec. 109, 413.

Ross, M. (1968) The fine structure and development of the peritubular contractile cell component in the seminiferous tubules of the mouse. Am. F. Anat. 121, 523.

Ross, M. H. \& Long, I. R. (1966) Contractile cells in human seminiferous tubules. Science, N.Y. 153, 1271.

Setchell, B. P. (1967a) The blood-testicular fluid barrier in sheep. F. Physiol., Lond. 189, 63P.

Setchell, B. P. (1967b) Fluid secretion by the testis. F. Reprod. Fert. 14, 347.

Voglmayr, J. K., Wartes, G. M. H. \& Setchell, B. P. (1966) Studies on spermatozoa and fluid collected directly from the testis of the conscious ram. Nature, Lond. 210, 861. 